\title{
Experimental Research on Casting Concrete of Composite Shear Wall with Steel Tubes and Filled Concrete
}

\author{
Lili Hu, Xiaoqiang Gao \\ Hang xiao steel structure CO.LTD, China
}

Keywords: composite shear wall with steel tubes and filled concrete; Pouring Concrete; deformation of steel tube;

\begin{abstract}
Pouring concrete of composite shear wall with steel tubes and filled concrete is tested in this paper. Conclusions are as follows: In case of pouring concrete height not exceeding $9 \mathrm{~m}$, the deformation and stress of steel tube is small; in the hardened concrete process, the deformation of steel tube reduces, and stress of steel tube dissipates. By only changing slump and aggregating diameter, ordinary concrete cannot guarantee concrete quality without vibration.
\end{abstract}

\section{Introduction}

In recent years, the research hot spots of the lateral force resisting systems for steel structures mainly is focused on various forms of composite steel plate shear walls, especially on various forms of concrete filled double-steel-plate composite shear walls [1,2,3,4]. However, during the construction process of the structure, double-steel-plate composite shear walls needs to be erected firstly, and then concrete is casted into double-steel-plate walls. Therefore, the requirement in fluidity of the concrete is high. In the process of casting concrete, the most important is making the concrete flow steadily between the two steel plates and controling the flow direction of concrete $[5,6]$. This paper mainly studys the forming quality of concrete in the double-steel-plate walls and the influence of casting process on steel tubes by the experiment of casting concrete in composite shear wall with steel tubes.

\section{Experimental program}

There is totally one specimen in this test, the material of steel is Q235B, the thickness of steel tubes is $4 \mathrm{~mm}$, the steel tube is $\mathrm{U} 130 \mathrm{X} 240 \mathrm{~mm}$, the height to thickness ratio is 60 . The thickness of wall specimen is $130 \mathrm{~mm}$, the width is $964 \mathrm{~mm}$.

The height of specimen is $9 \mathrm{~m}$, round holes are drilled at the height of $3 \mathrm{~m}$ and $6 \mathrm{~m}$. And the specimen is penetrated by reinforcing bars before pouring concrete, the distance of bars is 140 or 100 $\mathrm{mm}$. A total of 32 reinforcing bars are needed, the length of it is 150 , the diameter is $12 \mathrm{~mm}$.After penetrating to round holes, reinforcing bars are weld to steel palte.

Ordinary concrete of C30 is used in the experiment. In order to avoid the concrete aggregate was too large, the maximum nominal diameter of coarse aggregate required $25 \mathrm{~mm}$ at most. The slump flow of concrete is 635 at the beginning of the test.

As shown in Figure 1, Concrete is casted from tube 1 to tube 2.

As shown in Figure 2, five test points are arranged. The distance from test point 1(front of tube 1), test point 3(tube 2), test point 4(tube 3), test point 5(tube 4) to the floor is $300 \mathrm{~mm}$ and the distance from test point 2 (obverse of tube 1) to the floor is $400 \mathrm{~mm}$. After 1.1 hours of pouring, test point 2 is moved to test point 5 (tube 4). 


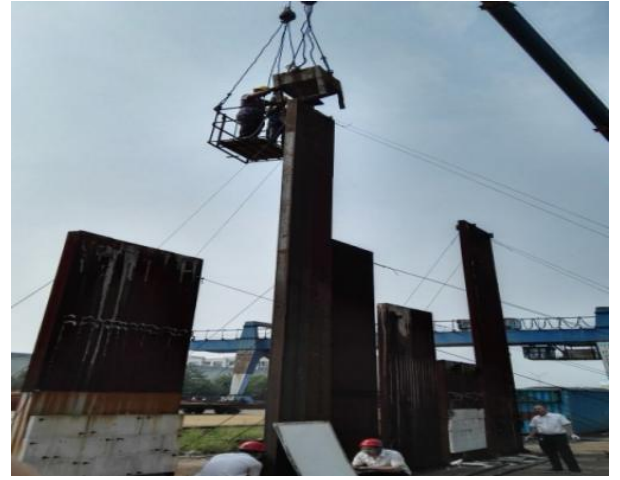

(a) casting Concrete

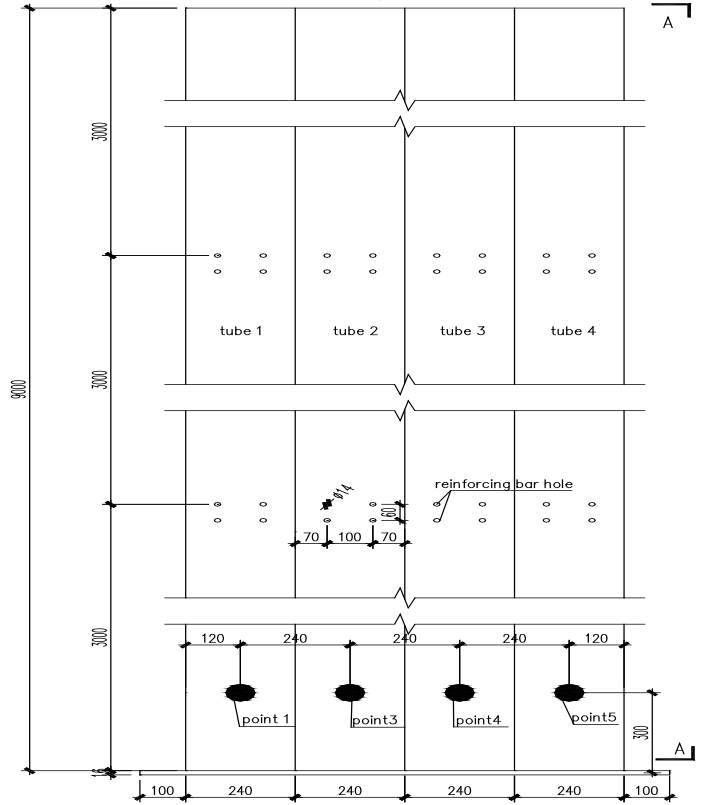

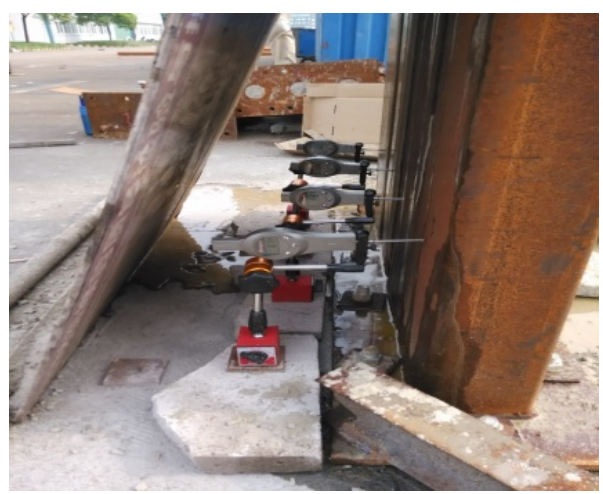

(b) test points

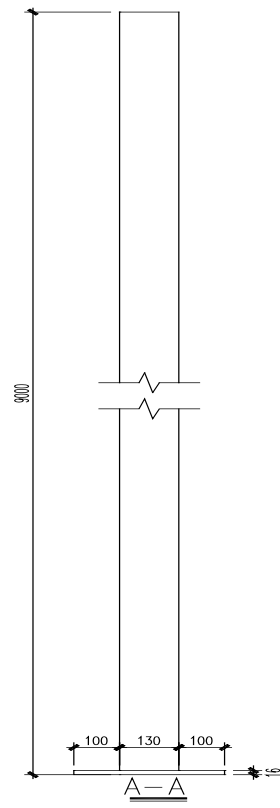

(c) Dimension of specimen

Fig.1 Dimension and detailing of specimen

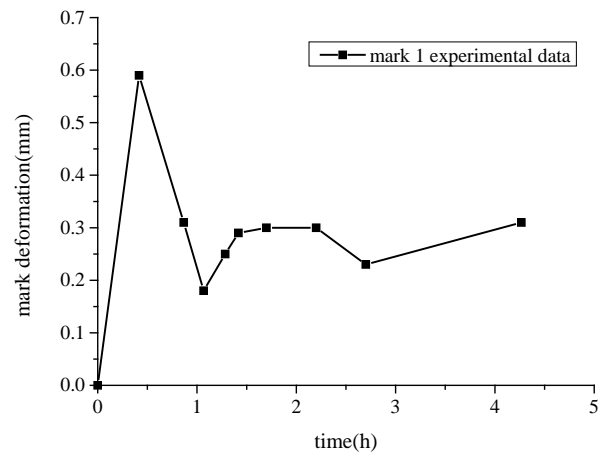

(a) tube 1

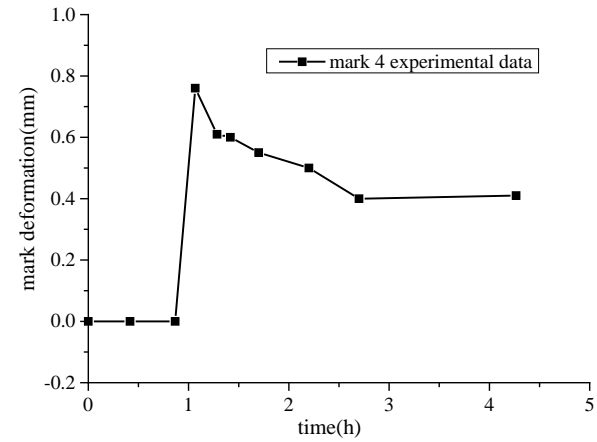

(c) tube 3

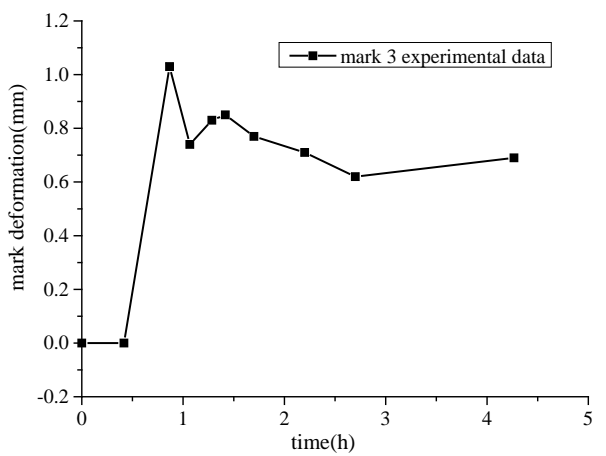

(b) tube 2

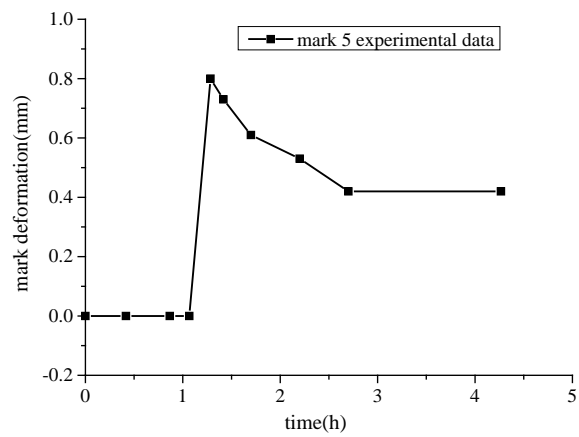

(d) tube 4

Fig.2 Deformation-time curve of tube 


\section{Experimental results}

Weld between steel tubes. The Weld damage is not found between steel tubes during the experiment process. The phenomenon proves that the bearing capacity of the weld meet pressure of $9 \mathrm{~m}$ height concrete. 3mm depth of fusion can meet the requirement of the bearing capacity during construction.

Deformation of tube. Casting in steel tube cause little impact to the adjacent empty steel tube, there is no measurement of deformation in it. Deformation retraction of the tube 1 caused by casting in tube 2 is $0.3 \mathrm{~mm}$; deformation retraction of the tube 2 caused by casting in tube 3 is $0.29 \mathrm{~mm}$; casting in steel tubes can cause the deformation decrease in adjacent steel tube but can not influence the third steel tube.

As it can be seen from Figure 2, with the increase of the hardened time of concrete, the deformation of the steel tubes gradually decreases. The maximum reduction is $0.28 \mathrm{~mm}$ (tube 1 ), $0.34 \mathrm{~mm}$ (tube 3), $0.34 \mathrm{~mm}$ (tube 3), $0.38 \mathrm{~mm}$ (tube 3). After 4.5 hours, the maximum deformation is $0.69 \mathrm{~mm}$ (tube 3 ), the minimum deformation is $0.31 \mathrm{~mm}$ (tube 1 ), the average deformation is $0.45 \mathrm{~mm}$.

By measuring the location of 1 and 2, the maximum deformation is located $300-400 \mathrm{~mm}$ from the bottom of the specimen.

Effect of reinforcing bars. It can be seen from Figure 3 that, after the steel plate is cut, the concrete is well formed without any defects. It is proved that the the setting of reinforcing bars will not affect the concrete quality.

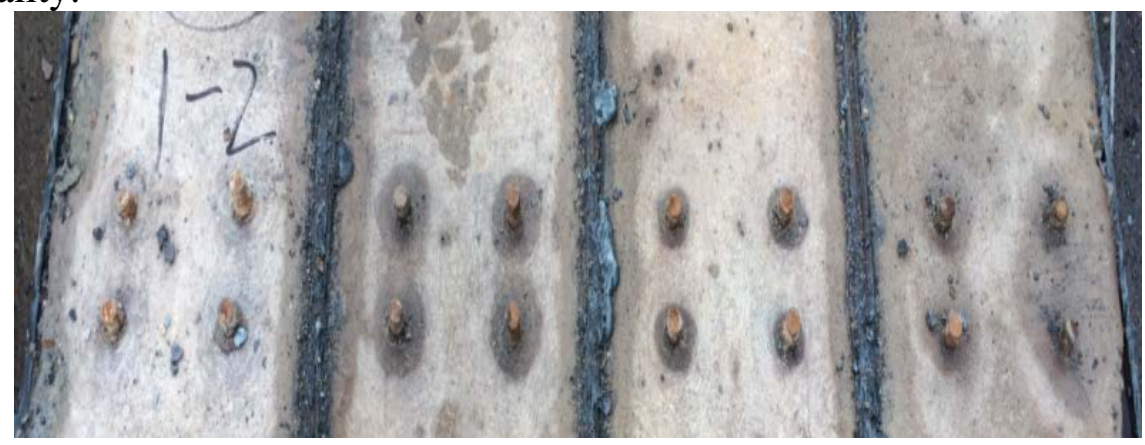

Fig.3 Concrete surface at reinforcing bars

(5) the surface quality of concrete

No cracks, slags, shape defects, looseness are found according to the requirement of cast-in-situ concrete structure in Code for acceptance of constructional quality of concrete structures (GB50204-2002, China).

But as it can be seen from Figure 4, at the distance of 3m from the top of the member, there is a point-like hole with depth of approximately $4 \mathrm{~cm}$; in the middle and at the edge of the steel tube, a long strip hole which is approximately longitudinal length of $12 \mathrm{~cm}$, width of $3 \mathrm{~cm}$, a depth of $4 \mathrm{~cm}$. therefore, hole defects are found.

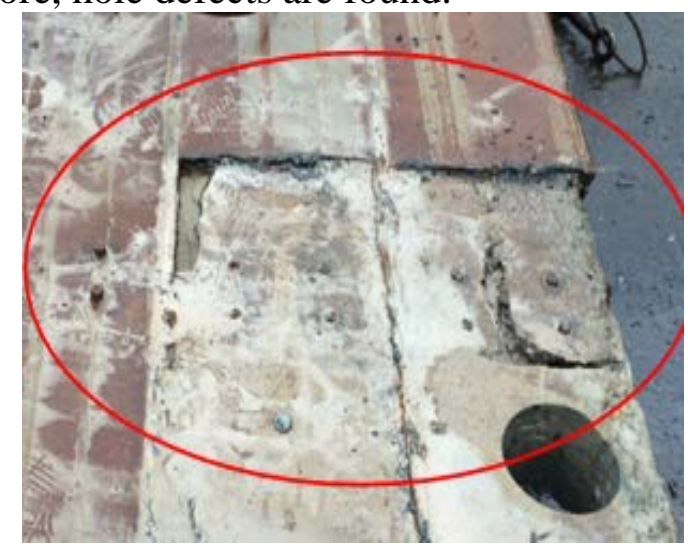

(a) Concrete surface at $6 \mathrm{~m}$ from the top of the member

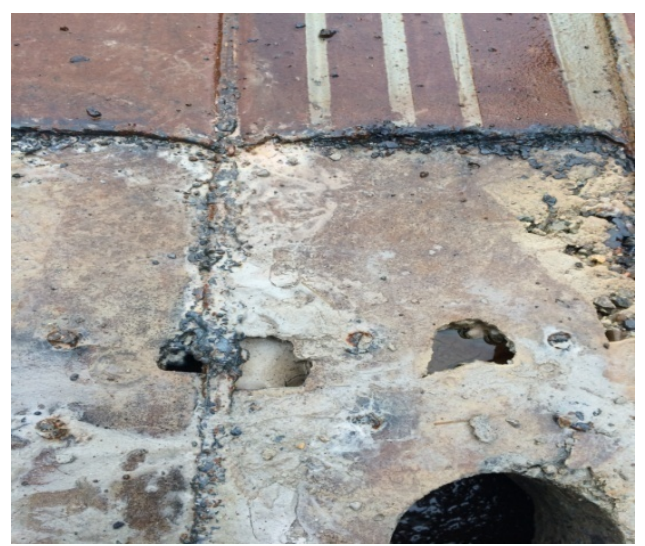

(b)Concrete surface at $3 \mathrm{~m}$ from the top of the member

Fig.4 Surface quality of concrete 
As it can be seen from Figure 5, a honeycomb (the exposed stones, a small amount of sand gathered and no cement) with longitudinal length of approximately $50 \mathrm{~cm}$ and width of $5 \mathrm{~cm}$ appear in the middle of a steel tube at the distance of $0.2-1 \mathrm{~m}$ from the top of the member. A honeycomb with longitudinal length of approximately $40 \mathrm{~cm}$ and width of $8 \mathrm{~cm}$ appear in the middle of a steel tube at the distance of $3-3.5 \mathrm{~m}$ from the top of the member.

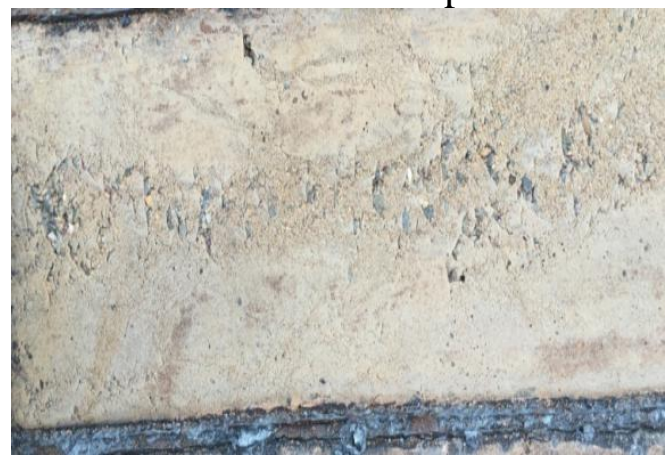

(a) honeycomb at $0.2-1 \mathrm{~m}$ from the top of the member

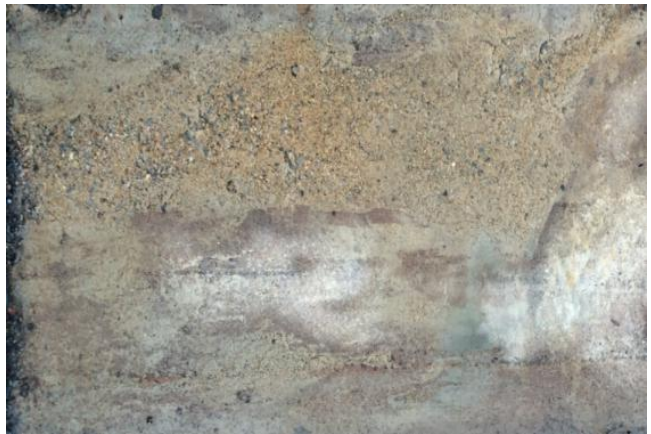

Fig.5 Honeycomb of concrete

Root of steel tube. It can be seen from Figure 6 that there is no concrete quality defect at the root of the member (9m from the top of the member), which root of steel tube need not to prevent it from jumping up when the concrete is casted.

\section{Conclusion}

When steel tube is not more than $9 \mathrm{~m}$ high,3mm depth of fusion can meet the requirement of the bearing capacity during construction.

With the increase of the hardened time of concrete, the deformation of the steel tubes gradually decreases. the maximum deformation is $0.69 \mathrm{~mm}$ (tube 3 ), the minimum deformation is $0.31 \mathrm{~mm}$ (tube 1 ), the average deformation is $0.45 \mathrm{~mm}$.

The setting of reinforcing bars will not affect the concrete quality. there is no concrete quality defect at the root of the member.

By only changed slump and aggregate diameter, ordinary concrete can not guarantee concrete quality with no vibration.

\section{References}

[1] J. van der Geer, J.A.J. Hanraads, R.A. Lupton, the art of writing a scientific article, J. Sci. [1] Nie Jian-guo, Bu Fan min, Fan Jian sheng. Quasi-static test on low shear-span ratio composite shear wall with double steel plates and infill concretr under high axial compression ratio[J]. Engineering Mechanics,2013, 30(6):60-66. (in Chinese)

[2] Hu Hongsong, Nie Jianguo. Deformability analysis of composite shear walls with double steel plates and infill concrete[J]. Journal of Building Structures,2013, 34(5):52-61. (in Chinese)

[3] Ma Kaize, Liu Boquan, Yan Hongliang, et al. Experimental inves tigation on aseismic behavior of double steel high strength concrete shear walls with high axial load ratio[J]. Engineering Mechanics,2014, 31(5):218-224. (in Chinese)

[4] Yang Guang, Zhao Zuozhou, Qian Jiaru, et al. Experimental study on seismic behavior of a new type of concrete filled steel tube composite shear walls[J]. Building Structure,2014, 44(7):93-98. (in Chinese)

[5] Wang Wenda, Yu Qing. Behavior of square steel tubular columns during concrete pouring[J]. Tsinghua Univ (Sci\&Tech),2013, 53(1):6-11. (in Chinese)

[6] Yu Qin. Discussion on the process control method of pouring quality of core concrete in concrete-filled steel tubes[J]. Industrial Construction,2008,138(9):104-106. (in Chinese) 